Slavica

bruxellensia

\section{Slavica bruxellensia}

Revue polyphonique de littérature, culture et histoire

slaves

$3 \mid 2009$

Pensée des hommes

\title{
László Földényi, Dostoïevski lit Hegel en Sibérie et fond en larmes
}

\section{Giulia Gigante}

\section{OpenEdition}

\section{Journals}

Édition électronique

URL : http://journals.openedition.org/slavica/216

DOI : 10.4000/slavica.216

ISSN : 2034-6395

\section{Éditeur}

Université libre de Bruxelles - ULB

\section{Édition imprimée}

Pagination : 104-105

ISSN : 2031-7654

Référence électronique

Giulia Gigante, «László Földényi, Dostoïevski lit Hegel en Sibérie et fond en larmes », Slavica bruxellensia [En ligne], 3 | 2009, mis en ligne le 15 juin 2009, consulté le 22 septembre 2020. URL : http:// journals.openedition.org/slavica/216 ; DOI : https://doi.org/10.4000/slavica.216

Ce document a été généré automatiquement le 22 septembre 2020

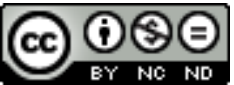

Les contenus de Slavica bruxellensia sont mis à disposition selon les termes de la Licence Creative Commons Attribution - Pas d'Utilisation Commerciale - Pas de Modification 3.0 France. 


\title{
László Földényi, Dostoïevski lit Hegel en Sibérie et fond en larmes
}

\author{
Giulia Gigante
}

\section{RÉFÉRENCE}

László Földényi, Dostoïevski lit Hegel en Sibérie et fond en larmes, Paris, Actes Sud, Paris, 2008, 64 p. Traduit du hongrois par Natalia Zaremba-Huzvai et Charles Zaremba. 
1

Ce bref essai de László Földényi, propose une lecture éclairante qui ouvre de nouvelles perspectives dans l'exégèse de la poétique de Dostoevskij. Le penseur hongrois, qui est un spécialiste de philosophie esthétique et professeur de littérature comparée à l'Université de Budapest, s'y engage dans une entreprise originale et passionnée qui naît de la conviction d'avoir "deviné » les œuvres de Hegel que l'écrivain russe aurait lu pendant son exil à Semipalatinsk, un bourg du Sud de la Sibérie. Celui-ci y avait été déporté au printemps 1854, après quatre ans de bagne. Földényi suppose (à partir du fait certain que le procureur Wrangel s'était lié d'amitié avec Dostoevskij et lui fournissait de nombreux livres, dont des œuvres de Hegel) que l'écrivain eut l'occasion de lire les Leçons sur la philosophie de l'histoire du philosophe allemand. Il imagine la réaction que l'auteur russe a pu avoir en découvrant que, selon Hegel, les idées pour lesquelles il avait été condamné à mort avant d'être gracié, envoyé au bagne et enfin exilé, que ses souffrances et celles de tous ses compagnons de mésaventure étaient dépourvues de signification en raison de leur situation géographique. En effet, Hegel considérait la Sibérie, tout comme l'Afrique, dépourvue de tout intérêt et, en conséquence, qu'elle ne pouvait pas entrer dans l'Histoire.

Földényi présume qu'à la première réaction instinctive - les larmes de désespoir qui inspirent le titre du livre - aurait succédé une réaction intellectuelle, plus articulée, à l'origine d'un tournant dans la pensée de Dostoevskij. Ce fut peut-être alors que l'écrivain comprit que dans la vie il y a des aspects qui ne peuvent pas être encadrés par l'Histoire. À ce moment là, il saisit que « l'Histoire ne révèle sa propre essence qu'à ceux qu'elle a au préalable exclus d'elle-même ». L'interprétation rationnelle de l'histoire délivrée par Hegel exclut tout ce qui échappe à la logique, tous les éléments incontrôlables de la vie humaine, tels que les souffrances, les instincts, les angoisses, les désirs, qui deviennent de purs accidents (y compris la mort de milliers d'individus). Or, ces éléments bouillonnants que le penseur allemand essaie de refouler, de tenir à l'écart suscitent le plus grand intérêt chez le romancier russe.

Pour Hegel, la Sibérie était effrayante parce qu'obscure, mystérieuse, incompréhensible pour l'esprit humain. Dostoevskij, lui, était convaincu que la Sibérie était l'Enfer avec toutes les horreurs que cela impliquait mais bénissait le sort d'y avoir été déporté car ce malheur lui avait permis de survivre à la rationalité grise du processus historique hégélien et donc, finalement, de gagner son salut. Il arriva jusqu'au paradoxe et affirma, en discutant avec Vsevolod Solov'ëv, le frère du philosophe, qu'en Sibérie il avait connu le véritable bonheur, que c'est à cette époque qu'il avait conçu ses meilleures idées : «c'est là que je me suis senti moi-même, (...) que j'ai senti le Christ, 
(...) l'homme russe, et c'est là que j'ai senti que j'étais russe moi aussi, fils du peuple russe ». Les expériences vécues dans cet Enfer lui ont permis d'acquérir une connaissance approfondie de l'homme russe, de découvrir les abîmes cachés de l'âme humaine. C'est en Sibérie qu'il apprit à sonder l'esprit humain, à explorer les contradictions et la complexité de la psyché sans craindre ce qu'il pouvait y déceler.

4 Sa façon d'écrire change dans les œuvres composées après l'exil et il ne s'agit pas d'une coïncidence. Sans l'initiation sibérienne, des personnages comme le prince Myškin et Nastas'ja Filippovna, RaskoL'nikov et Ivan Karamazov n'auraient probablement pas existé. Dostoevskij détestait la conventionalité, la médiocrité, la grisaille du quotidien qui constituaient pour lui le véritable Enfer, "l'Enfer terne de l'Europe » à fuir absolument. À l'Europe de Hegel qui le refusait, il oppose la Sibérie, qui était au moins "pittoresque " et vivante. C'est justement de la révolte contre l'aplatissement et l'ordinaire que naissent ses héros rebelles: des personnages authentiques, imprévisibles, passionnés, tourmentés et contra-dictoires.

\section{INDEX}

Index géographique : Russie, Sibérie

Mots-clés : littérature russe, philosophie russe

Index chronologique : XIXe siècle

\section{AUTEURS}

\section{GIULIA GIGANTE}

Traductrice (Bruxelles) 